\title{
Opisthorchis viverrini metacercarial infection in cyprinid fish in Nakhon Phanom Province, Northeastern Thailand
}

\author{
Laoprom, N. ${ }^{1}$, Prathummang, S. ${ }^{2}$, Chuangchaiya, S. ${ }^{3 *}$, Navanesan, S. ${ }^{4}$, Munajat, M.B. ${ }^{5}$, \\ Suwannatrai, A.T. ${ }^{6}$, Idris, Z.M. ${ }^{{ }^{*}}$
}

${ }^{1}$ Department of General Science, Faculty of Science and Engineering, Kasetsart University, Chalermphrakiat Sakon Nakhon Province Campus, Sakon Nakhon, 47000, Thailand

${ }^{2}$ Hue Phon Health Promotion Hospital, Mueang Nakhon Phanom, Nakhon Phanom, 48000, Thailand

${ }^{3}$ Department of Community Health, Faculty of Public Health, Kasetsart University, Chalermphrakiat Sakon Nakhon Province Campus, Sakon Nakhon, 47000, Thailand

${ }^{4}$ Secretariat for Medical Research and Innovation, Faculty of Medicine, Universiti Kebangsaan Malaysia, 56000 Cheras, Kuala Lumpur, Malaysia ${ }^{5}$ Department of Parasitology and Medical Entomology, Faculty of Medicine, Universiti, Kebangsaan Malaysia, 56000 Cheras, Kuala Lumpur, Malaysia ${ }^{6}$ Department of Parasitology, Faculty of Medicine, Khon Kaen University, Khon Kaen, 40002, Thailand

*Corresponding author: zulkarnain.mdidris@ukm.edu.my

\section{ARTICLE HISTORY}

Received: 17 September 2020 Revised: 3 February 2021

Accepted: 6 February 2021

Published: 30 April 2021

\begin{abstract}
Opisthorchiasis is endemic in parts of Southeast Asia, including the northern and northeastern regions of Thailand. In these regions, the transmission by fish intermediate hosts has received little attention. We investigated the intensity of Opisthorchis viverrini metacercariae (OV MC) in wild cyprinid fishes from five districts within the Nakhon Phanom Province, Northeast Thailand. Fishes were procured from local markets in five districts throughout three different seasons (hot, rainy and cold) between February 2018 and January 2019. The samples were identified, counted and weighed before metacercariae detection was performed via the artificial digestion method. A total of 2,149 freshwater fishes, representing 20 species were collected. The fish most commonly contaminated with OV MC were Anematichthys repasson and Hampala dispar. The intensity of OV MC in Nakhon Phanom was $0.23 \mathrm{OV} \mathrm{MC/fish} \mathrm{and} \mathrm{varied} \mathrm{among} \mathrm{districts,} \mathrm{ranging} \mathrm{from} 0.07$ to 0.52 . A low intensity of OV $\mathrm{MC} /$ fish (defined as $\leq 1$ cyst) was found in all three different seasons in the Nakhon Phanom Province; hot season (0.55), cold season (0.22) and the rainy season (0.13). The intensity of OV MC/fish was moderate (defined as $>1$ cyst) in the Renu Nakhon district (2.5) in the hot season. By fish species, $H$. dispar yielded the highest, with a moderate intensity of 2.1. In natural freshwater cyprinid fish in Nakhon Phanom, OV MC infection is endemic with intensity rates varying according to district, season and fish species.
\end{abstract}

Keywords: Opisthorchis viverrini; cyprinid fish; metacercariae; season; Thailand.

\section{INTRODUCTION}

The incidence of Opisthorchis viverrini infection has long been a major public health issue affecting Southeast Asian countries, especially those along the Greater Mekong Subregion (Cambodia, Vietnam, Laos, Myanmar, and Thailand) (Sithithaworn et al., 2012; Suwannatrai et al., 2018). An estimated 10 million people in Southeast Asia are at risk of $O$. viverrini infection (Aung et al., 2017). In Thailand, eight million people have been infected with this parasite, with the highest prevalence recorded in the north-eastern region (Andrews et al., 2018).

Aside from its mammalian definitive host in humans and reservoir hosts, mainly in cats and dogs, the complex life cycle of $O$. viverrini involves two aquatic intermediate hosts, freshwater snails of the genus Bithynia sp. as well as the Cyprinidae family of freshwater fishes (Khieu et al., 2019). The complex life cycle of $O$. viverrini and its different hosts, particularly the cyprinid fish, may provide several possible targets that could be used in controlling the spread of this parasite. These freshwater fishes are abundant and serve as the primary source of protein for many rural populations of Southeast Asian countries. They are easily caught and are typically consumed either raw or used in traditional dishes such as koi-pla, lab-pla, pla-som, and pla-ra; all of which involves no or inadequate cooking (Chuboon et al., 2005; Prasongwatana et al., 2013). An understanding of the distribution and intensity of $O$. viverrini metacercariae (OV $\mathrm{MC}$ ) in these fishes is crucial in managing opisthorchiasis.

Among the 20 provinces in northeastern Thailand, Nakhon Phanom has consistently shown a high prevalence of $O$. viverrini infections (Thaewnongiew et al., 2014). Previous 
studies in the province revealed that $O$. viverrini infections among communities with high raw fish consumption stood between 15-20\% (Chuangchaiya et al., 2019, 2020). To the best of our knowledge, no previous reports have specifically addressed the variation in intensities of OV MC in fish species among districts in Nakhon Phanom. In addition to the diversity of fish species, more current data are needed to gain more understanding on the patterns of infection dynamics of $O$. viverrini in different endemic areas. In the present study, we examined the intensity and spatial distribution of OV MC in freshwater cyprinid fish in Nakhon Phanom Province, Thailand. We also evaluated the effect of geographical location, seasonal changes, and intermediate host specificity on the intensity of OV MC.

\section{MATERIALS AND METHODS}

\section{Fish collection}

Freshwater fish were purchased from local markets in five districts within the Nakhon Phanom Province, between February 2018 and January 2019. This covered three different seasons namely hot (February-May), rainy (June-September) and cold (October-January). These markets were chosen based upon their proximity with primary rivers; Mueang Nakhon Phanom (Bung Kor River), Nakae (Bung River), Na Thom (Wang Nong River), Renu Nakhon (Pak Bung River) and Si Songkhram (Song Khram River). Local small-scale fish dealers confirmed that all fish were caught from the freshwater bodies in the study areas using fishing net trapping overnight and were harvested in the morning. Furthermore, cyprinid fish present in the study areas were wild and naturally bred species and were classified as lowvalue fish. Five to $14 \mathrm{~kg}$ of fish were collected in each district throughout the three seasons. Fish were kept in labeled plastic bags and transported within three days to the Parasitology Laboratory at the Faculty of Science and Technology, Kasetsart University, Chalermphrakiat Sakon Nakhon Province Campus. Fish species were identified and grouped with the aid of the FishBase (http://www.fishbase. in/search.php). All information on the examined fish, including species, weight, count, and geographical origin was recorded.

\section{Examination of $O$. viverrini metacercariae}

Upon thorough washing with tap water, pools of the same fish species from each sampling site were inspected for OV MC using the standard pepsin digestion method as described previously (Pinlaor et al., 2013; Chai et al., 2014). Briefly, fish were finely homogenized in a blender and mixed with $0.25 \%$ pepsin-1.5\% $\mathrm{HCl}$ (Sigma-Aldrich, Missouri, USA) in $0.85 \% \mathrm{NaCl}$ solution. The mixture was incubated in a shaking water bath at $37^{\circ} \mathrm{C}$ for two to three hours. The digested fish was then filtered through a series of metal sieves of different pore sizes (i.e. 1000, 300 and $106 \mu \mathrm{m}$ ). The final filtrate was sedimented in conical jars with several washes of $0.85 \%$ $\mathrm{NaCl}$ until the supernatant became clear. Finally, the sediment was examined under a stereomicroscope for metacercariae, performed by two experienced technicians. The metacercariae were identified based on their morphological characteristics.

\section{Spatial analysis}

The inverse-distance weighted (IDW) spatial interpolation method was used to describe the distribution intensity of OV MC among cyprinid fishes in each season. The base-map data for administrative boundaries at the district level of
Nakhon Phanom Province and rivers were obtained from the DIVA-GIS website (www.diva-gis.org). All analyses were performed using ArcGIS version 10.5.1 (ESRI Inc., California, USA).

\section{Statistical analysis}

The mean intensity of OV MC was calculated according to Bush et al. (1997) by counting the number of OV MC detection divided by the number of fish or by the weight of fish in $\mathrm{kg}$ (Bush et al., 1997). The intensities were either classified as low ( $\leq 1$ cyst) or moderate (>1 cyst). The variation of mean intensity of OV MC was analyzed using GraphPad Prism version 7 (GraphPad Software Inc., California, USA).

\section{RESULTS}

Freshwater fish species for 0 . viverrini metacercarial infection A total of 2,149 freshwater fishes were collected, comprising of 20 different species; Anematichthys apogon, Anematichthys repasson, Barbonymus altus, Barbonymus gonionotus, Cirrhinus microlepis, Cyclocheilichthys enoplos, Gymnostomus lineatus, Hampala dispar, Hampala macrolepidota, Henicorhynchus lineatus, Henicorhynchus siamensis, Labeo chrysophekadion, Labiobarbus leptocheila, Mystacoleucus marginatus, Osteochilus vittatus, Osteochilus melanopleurus, Probarbus jullieni, Puntioplites proctozysron, Puntius brevis, and Thynnichthys thynnoides. Of these, six species were found to be infected with OV MC namely $A$. repasson, $H$. dispar, $H$. lineatus, $M$. marginatus, $O$. vittatus and $T$. thynnoides. Four of the infected fish species $(H$. dispar, $M$. marginatus, $A$. repasson, and $O$. vittatus) were from Mueang Nakhon Phanom, three $(H$. dispar, A. repasson, and $H$. lineatus) from $\mathrm{Na}$ Kae and only one from Renu Nakhon ( $T$. thynnoides) and $\mathrm{Na}$ Thom (A. repasson). No infected fish were found in $\mathrm{Si}$ Songkhram. The species most commonly infected with OV $\mathrm{MC}$ were $A$. repasson and $H$. dispar. The overall distribution of OV MC infection in freshwater fish collected from five districts is shown in Table 1.

Table 1. Species of fish, number of fish, weight, and number of Opisthorchis viverrini metacercariae (OV MC)-infected fish in all five districts in Nakhon Phanom Province, northeast Thailand

\begin{tabular}{lccc}
\hline Species of fish & $\begin{array}{c}\text { No. of } \\
\text { fish }\end{array}$ & $\begin{array}{c}\text { Total weight } \\
\text { weight (kg) }\end{array}$ & $\begin{array}{c}\text { No. of } \\
\text { OV MC }\end{array}$ \\
\hline Anematichthys apogon & 28 & 0.41 & 0 \\
Anematichthys repasson & 326 & 7.64 & 16 \\
Barbonymus altus & 64 & 7.74 & 0 \\
Barbonymus gonionotus & 15 & 1.66 & 0 \\
Cirrhinus microlepis & 2 & 0.54 & 0 \\
Cyclocheilichthys enoplos & 18 & 2.48 & 0 \\
Gymnostomus lineatus & 38 & 1.28 & 0 \\
Hampala dispar & 80 & 9.29 & 63 \\
Hampala macrolepidota & 26 & 3.84 & 0 \\
Henicorhynchus lineatus & 14 & 0.59 & 13 \\
Henicorhynchus siamensis & 246 & 10.48 & 0 \\
Labeo chrysophekadion & 4 & 0.49 & 0 \\
Labiobarbus leptocheila & 440 & 14.74 & 0 \\
Mystacoleucus marginatus & 46 & 1.33 & 27 \\
Osteochilus vittatus & 203 & 7.22 & 1 \\
Osteochilus melanopleurus & 59 & 3.18 & 0 \\
Probarbus jullieni & 54 & 2.33 & 0 \\
Puntioplites proctozysron & 119 & 6.35 & 0 \\
Puntius brevis & 37 & 4.42 & 0 \\
Thynnichthys thynnoides & 330 & 11.15 & 10 \\
Total & 2149 & 97.14 & \\
\hline & & & \\
\hline
\end{tabular}




\section{O. viverrini metacercarial intensity in freshwater fish}

In general, the overall intensity of OV MC infection in Nakhon Phanom was low ( $0.23 \mathrm{OV} \mathrm{MC/fish)} \mathrm{and} \mathrm{varied} \mathrm{among} \mathrm{districts}$ ranging from 0.07 to 0.52 . Similarly, a low intensity of OV MC per fish was found in all three different seasons in Nakhon Phanom; hot season (0.55), followed by cold season (0.22) and the rainy season (0.13). Nevertheless, the intensity of OV MC per fish was moderate in Renu Nakhon (2.5) in the hot season and only observed in low intensity in $\mathrm{Na}$ Tom (0.13) during the rainy season (Table 2 ).

Overall, fish species in increasing order of OV MC mean intensity per fish were $O$. vittatus $(0.01), A$. repasson (0.06), $T$. thynnoides (0.07), M. marginatus (0.59), $H$. lineatus (0.93) and $H$. dispar (2.10). When stratified by district, moderate intensity of OV MC per fish was found only in $H$. dispar (2.73), when compared to the three other infected species of fish in Mueang Nakhon Phanom. A low intensity of OV MC per fish was found in three infected fish species in $\mathrm{Na}$ Kae (range $0.04-0.93)$, followed by $A$. repasson $(0.10)$ in $\mathrm{Na}$ Thom, and T. thynnoides (0.07) in Renu Nakhon (Table 2).

\section{Predicted 0 . viverrini metacercarial intensity}

The predicted intensity distribution of OV MC in cyprinid fish in each season is shown in various grades of risk in the areas, i.e. high (dark brown), moderate (light yellow), and low (dark blue-green) (Figure 1). By season, the high intensity of OV MC in cyprinid fish in cold, rainy and hot seasons were in Mueang Nakhon Phanom, $\mathrm{Na}$ Thom, and Renu Nakhon districts, respectively.

\section{DISCUSSION}

Despite the relative success of praziquantel treatment as well as health care and education programs in suppressing the prevalence of $O$. viverrini infection from $34.6 \%$ in 1980 to $15.7 \%$ in 2000 (Sripa et al., 2015), opisthorchiasis remains persistent in northeastern Thailand (Boonjaraspinyo et al., 2013; Andrews et al., 2018). This prompted us to look into the possible factors, such as geography, seasonality, and intermediate host preference, that may have an impact on the disease prevalence in northeastern Thailand. We conducted a study in the Nakhon Phanom Province as it has consistently shown an increased presence of $O$. viverrini infection.
A high metacercariae load in fishes is typically associated with high infection levels among the local population (Sithithaworn et al., 1997). In Nakhon Phanom, the prevalence of $O$. viverrini infections in humans stood at 40.9\% (Thaewnongiew et al., 2014). Accordingly, OV MC infected fishes were found in four out of the five sampled districts in the province. In the present study, Mueang Nakhon Phanom recorded both the highest OV MC intensity and the number of fish species in which the parasites were detected. As the capital of the province is located within the Mueang Nakhon Phanom district (Praweenwongwuthi et al., 2017), the higher population density translates to a higher demand for fish, which is a prime source of protein. This compels the need to import fishes caught in neighboring districts/regions that may have a high burden of $O$. viverrini. In recent times, an improved transportation system in the Lower Mekong Subregion has given rise to the marketing of cyprinid fish by fishermen to intermediaries, who will then be able to distribute them across a wider network than was previously possible (Kim et al., 2017). This in turn may lead to the dispersion of $O$. viverrini to regions beyond its natural boundaries.

Looking at the distribution of OV MC among the species of fish examined, $\boldsymbol{H}$. dispar appeared to have the highest infection burden among those which tested positive for the parasite. This observation was consistent with previous studies that presented $H$. dispar as among the most heavily $O$. viverrini-infected fish, be it in terms of prevalence or intensities (Sithithaworn et al., 1997; Pinlaor et al., 2013; Manpratum et al., 2017; Prakobwong et al., 2017; Namsanor et al., 2020). The higher incidence of infection in this species may be attributed to its larger body mass which provides an easier target for the parasites (Sithithaworn et al., 1997; Namsanor et al., 2020).

OV MC burden in one fish species may differ by district. In the present study, $A$. repasson was present in all five monitored districts but showed variability in the presence and intensity of OV MC. Infected fish were caught in three of the five districts with OV MC intensities ranging from 0.04 in Na Kae to 0.15 in Mueang Nakhon Phanom. Similarly, H. dispar possessed the highest intensity among infected fish caught in Mueang Nakhon Phanom but was free of OV MC infection in $\mathrm{Na}$ Thom. Both biotic (e.g. presence of Bithynia snails) and abiotic (e.g. temperature and flow-rate of water) factors could

Table 2. District level intensity of Opisthorchis viverrini metacercariae (OV MC) infection in cyprinid fish in Nakhon Phanom Province by season and species of infected fish

\begin{tabular}{|c|c|c|c|c|c|c|c|c|c|c|}
\hline \multirow{2}{*}{ District } & \multicolumn{4}{|c|}{ Mean intensity by season (OV MC/fish) } & \multicolumn{6}{|c|}{ Mean intensity by fish species (OV MC/fish) } \\
\hline & Overall & Hot & Rainy & Cold & H. dispar & M. marginatus & A. repasson & O. vittatus & H. lineatus & T. thynnoides \\
\hline $\begin{array}{l}\text { Mueang Nakhon } \\
\text { Phanom }\end{array}$ & $\begin{array}{c}0.52 \\
(92 / 178)\end{array}$ & $\begin{array}{c}0.79 \\
(88 / 112)\end{array}$ & - & $\begin{array}{l}0.50 \\
(4 / 8)\end{array}$ & $\begin{array}{c}2.73 \\
(60 / 22)\end{array}$ & $\begin{array}{c}0.59 \\
(27 / 46)\end{array}$ & $\begin{array}{c}0.15 \\
(4 / 26)\end{array}$ & $\begin{array}{c}0.01 \\
(1 / 84)\end{array}$ & - & - \\
\hline Na Kae & $\begin{array}{c}0.12 \\
(22 / 191)\end{array}$ & $\begin{array}{c}0.19 \\
(19 / 98)\end{array}$ & - & $\begin{array}{c}0.13 \\
(3 / 24)\end{array}$ & $\begin{array}{l}0.38 \\
(3 / 8)\end{array}$ & - & $\begin{array}{c}0.04 \\
(6 / 169)\end{array}$ & - & $\begin{array}{c}0.93 \\
(13 / 14)\end{array}$ & - \\
\hline Renu Nakhon & $\begin{array}{c}0.07 \\
(10 / 148)\end{array}$ & $\begin{array}{c}2.50 \\
(10 / 4)\end{array}$ & - & - & - & - & - & - & - & $\begin{array}{c}0.07 \\
(10 / 148)\end{array}$ \\
\hline Si Songkhram & - & - & - & - & - & - & - & - & - & - \\
\hline Na Thom & $\begin{array}{c}0.10 \\
(6 / 59)\end{array}$ & - & $\begin{array}{c}0.13 \\
(6 / 45)\end{array}$ & - & - & - & $\begin{array}{c}0.10 \\
(6 / 59)\end{array}$ & - & - & - \\
\hline Overall & $\begin{array}{c}0.23 \\
(130 / 576)\end{array}$ & $\begin{array}{c}0.55 \\
(117 / 214)\end{array}$ & $\begin{array}{c}0.13 \\
(6 / 45)\end{array}$ & $\begin{array}{c}0.22 \\
(7 / 32)\end{array}$ & $\begin{array}{c}2.10 \\
(63 / 30)\end{array}$ & $\begin{array}{c}0.59 \\
(27 / 46)\end{array}$ & $\begin{array}{c}0.06 \\
(16 / 254)\end{array}$ & $\begin{array}{c}0.01 \\
(1 / 84)\end{array}$ & $\begin{array}{c}0.93 \\
(13 / 14)\end{array}$ & $\begin{array}{c}0.07 \\
(10 / 148)\end{array}$ \\
\hline
\end{tabular}




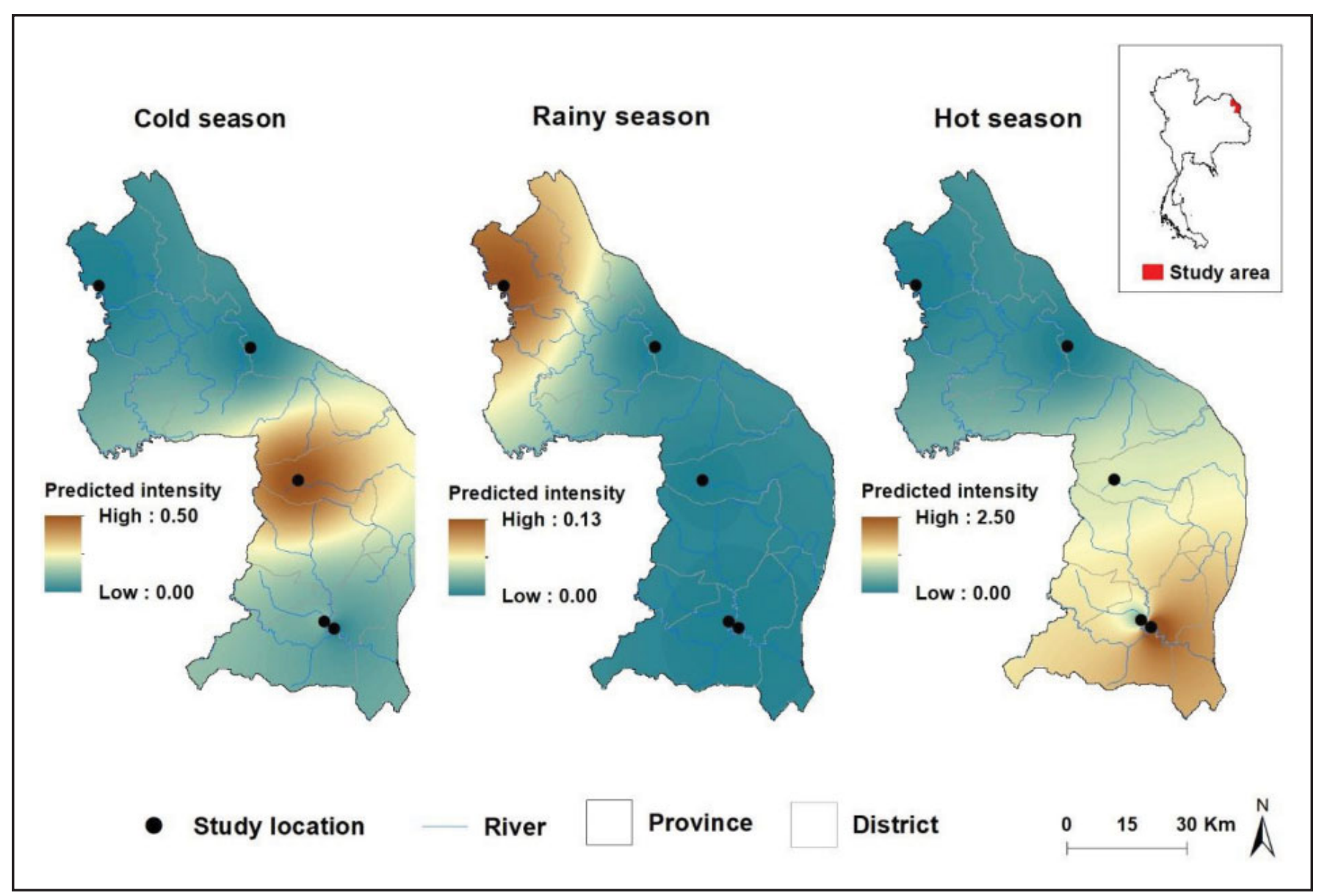

Figure 1. Predicted seasonal intensity of Opisthorchis viverrini metacercariae (OV MC) infection in cyprinid fish in Nakhon Phanom Province, northeast Thailand.

contribute to the geographic difference in parasite burden among fishes (Echaubard et al., 2017). A somewhat comparable observation was seen by Namsanor et al. (2020), whereby $H$. dispar and $P$. brevis caught from Mukdahan Province in Thailand showed varying average intensities of infection that corresponded with the levels of endemicity among humans in those areas (Namsanor et al., 2020).

The results in the current study generally indicate a higher intensity of cyprinid fish infected with $O$. viverrini during the dry season as compared to the cold and rainy seasons. This observation was consistent with previous studies in Cambodia that indicated a high metacercarial burden was present in the dry season as opposed to the wet season (Ngoen-klan et al., 2010; Touch et al., 2013; Namsanor et al., 2020). The lower infection among fish during the rainy season was attributed to the high flow-rate and freshwater pulse that would lead to the dilution of parasitic egg concentration as well as increase the presence of uninfected fishes downstream. Given the similarity in climate between Cambodia and Thailand, this explanation may apply to the present study. Nevertheless, the underlying mechanism driven by seasonality is not fully known, but it is believed that the physical availability of rainwater may facilitate the movement of faeces contaminated with eggs into bodies of water, allowing the eggs to be ingested by snail intermediate hosts as the first stage of their life cycle. Other hydrological conditions also support disease transmission, such as low water levels and a high prevalence of infection in the snail intermediate hosts in the cool-dry season (Namsanor et al., 2015).
Although rainwater and irrigated water increase the chance of eggs being passively transported to a suitable habitat for the Bithynia snail intermediate hosts, other local factors, such as temperature, play an important role in snail success (Prasopdee et al., 2015). The hot season (March through May) brings about environmental temperatures ranging from 33 to $36^{\circ} \mathrm{C}$. Prasopdee et al. (2015) showed that elevated temperatures (around $34^{\circ} \mathrm{C}$ ) were associated with a higher $O$. viverrini infection rate among the intermediate host (snails) (Prasopdee et al., 2015). Higher infection rates in snails could lead to a higher cercarial burden, leading to an increased infection among cyprinid fish. This may explain the high OV MC intensities observed in fishes caught during the hot season in the present study.

Contrary to the above arguments, Echaubard et al. (2017) showed that the hatching success and rate of infection among laboratory-cultivated $O$. viverrini metacercariae were negatively impacted by elevated temperatures $\left(>30^{\circ} \mathrm{C}\right)$ (Echaubard et al., 2017). Infection rates peaked at $30^{\circ} \mathrm{C}$ or below, while climate modeling pointed towards an increased transmission risk upon the onset of the rainy season. This observation was similar to those reported by Sithithaworn et al. (1997), whereby a higher burden was seen in the late rainy and winter seasons (July to January) with low burdens during the summer (March to June) (Sithithaworn et al., 1997). However, Echaubard et al. (2017) did acknowledge that their model did not account for numerous unknown and unmeasured environmental factors that may influence the infection rate of $O$. viverrini (Echaubard et al., 2017). One possible explanation is the lower infection rates may be 
counteracted by the release of larger numbers of $O$. viverrini eggs by a single infected host. The higher number of eggs in the calm water bodies due to low flow rates during the dry season, as mentioned earlier, could explain the higher intensities seen in the present study.

Despite the presence of government-run treatment and education programs aimed at creating awareness of risk factors (i.e. poor sanitation and consumption practices) and severity of this disease (Suwannatrai et al., 2018), O. viverrini remains a persistent issue in northeastern Thailand. As such, new methods in controlling the spread of $O$. viverrini is required. Although the significant and practicality have never been assessed, Echaubard et al. (2017) had suggested utilizing heat treatment in the septic system to overcome the spread of $O$. viverrini via faecal matters; based on their research showing increased mortality of the $O$. viverrini eggs at temperatures above $35^{\circ} \mathrm{C}$ (Echaubard et al., 2017). Similarly, Boueroy et al. (2019) also suggested a promising role of sewage heat treatment method, which was based on their findings that temperatures of 70 to $80^{\circ} \mathrm{C}$ for ten minutes could destroy the $O$. viverrini eggs (Bourey et al., 2019). In addition to this, Hinz et al. (1994) suggested coupling the timing of praziquantel treatment with periods of the year known to present minimal risk of infection with the intention of reducing re-infection rates and subsequent transmission events (Hinz et al., 1994). This would require a thorough understanding of the seasonal and environmental factors that may play a role in influencing the burden of $O$. viverrini in the fish as well as the Bithynia snails which act as an intermediary host.

A number of caveats should be considered in this study. First, our fish sample was incomplete because some species were not available in the seasonal samples. Second, size ranges of fish were not available for metacercarial analysis. Third, more study settings in various river wetlands are needed to determine the transmission dynamic pattern over a wider geographical area. Fourth, studies should take into account the location and type of water source (i.e. rivers, lakes or artificial aquaculture ponds), which would shed some light into conditions that favour the spread of OV MC.

In conclusion, we demonstrated that the intensities of OV MC in cyprinid fish varied among the five evaluated districts in the Nakhon Phanom Province, with seasonal changes and host preference possibly playing a determining role. The hot season, as well as the larger $H$. dispar, seemed to favor a higher metacercariae burden among fish from Nakhon Phanom Province. The findings from the present study may provide leads that could be translated into potential effective measures to control the development and spread of this infectious disease, especially in the high-risk northeastern region of Thailand.

\section{ACKNOWLEDGMENTS}

We would like to extend our gratitude to the communities and community leaders for their support and participation in the survey. We acknowledge Dr. Chim W. Chan from Osaka City University, Japan who has given us additional insights for the manuscript. This study was partially supported by the GGPM grant (Grant No. FF-2018-047) from the National University of Malaysia (UKM).

\section{Conflict of interests}

The authors declare no competing financial interest.

\section{REFERENCES}

Andrews, R.H., Sithithaworn, P. \& Petney, T.N. (2018). Opisthorchis viverrini: an underestimated parasite in world health. Trends in Parasitology 24: 497-501. https://doi.org/ 10.1016/j.pt.2008.08.011

Aung, W.P.P, Htoon, T.T., Tin, H.H., Thinn, K.K., Sanpool, O., Jongthawin, J., Sadaow, L., Phosuk, I., Rodpai, R. \& Intapan, P.M. (2017). First report and molecular identification of Opisthorchis viverrini infection in human communities from Lower Myanmar. PLoS One 12: e0177130. https://doi.org/ 10.1371/journal.pone.0177130

Boonjaraspinyo, S., Boonmars, T., Kaewsamut, B., Ekobol, N., Laummaunwai, P., Aukkanimart, R., Wonkchalee, N., Juasook, A. \& Sriraj, P. (2013). A cross-sectional study on intestinal parasitic infections in rural communities, northeast Thailand. The Korean Journal of Parasitology 51: 727-734. https://doi.org/10.3347/kjp.2013.51.6.727

Boueroy, P., Duenngai, K., Eamudomkarn, C., Sripan, P., Boonmars, T., Pumhirunroj, B., Artchayasawat, A., Songsri, J., Chomphumee, K. \& Rattanasuwan, P. (2019). Effect of temperature on the killing of Opisthorchis viverrini eggs in vitro. The Korean Journal of Parasitology 57: 49-53. https:// doi.org/10.3347/kjp.2019.57.1.49

Bush, A.O., Lafferty, K.D., Lotz, J.M. \& Shostak, A.W. (1997). Parasitology meets ecology on its own terms: Margolis et al. revisited. The Journal of Parasitology 83: 575-83.

Chai, J.Y., Sohn, W.M., Na, B.K., Yong, T.S., Eom, K.S., Yoon, C.H., Hoang, E.H., Jeoung, H.G. \& Socheat, D. (2014). Zoonotic trematode metacercariae in fish from Phnom Penh and Pursat, Cambodia. The Korean Journal of Parasitology 52: 3540. https://doi.org/10.3347/kjp.2014.52.1.35

Chuangchaiya, S., Laoprom, N. \& Idris, Z.M. (2019). Prevalence and associated risk factors of Opisthorchis viverrini infections in rural communities along the Nam Kam River of Northeastern Thailand. Tropical Biomedicine 36: 81-93.

Chuangchaiya, S., Navanesan, S., Jaichuang, S., Rahim, M.A.F.A. \& Idris, Z.M. (2020). Current prevalence of Opisthorchis viverrini infection and associated risk factors in Nakhon Phanom Province, Northeastern Thailand. Tropical Biomedicine 37: 986-999.

Chuboon, S., Wongsawad, C., Ruamsuk, A. \& Nithikathkul, C. (2005). Survival of Haplorchis taichui metacercariae in LabPla, Thai traditional food preparation. The Southeast Asian Journal of Tropical Medicine and Public Health 36(Suppl. 4): 110-111.

Echaubard, P., León, T., Suwanatrai, K., Chaiyos, J., Kim, C.S., Mallory, F.F., Kaewkes, S., Spear, R.C. \& Sripa, B. (2017). Experimental and modelling investigations of Opisthorchis viverrini miracidia transmission over time and across temperatures:implications for control. International Journal of Parasitology 47: 257-270. https://doi.org/10.1016/ j.ijpara.2016.10.007

Hinz, E., Saowakontha, S. \& Pipitgool, V. (1994). Opisthorchiasis control in northeast Thailand: proposal for a new approach. Applied Parasitology 35: 118-124.

Kim, C.S., Smith, J.F., Suwannatrai, A., Echaubard, P., Wilcox, B., Kaewkes, S., Sithithaworn, P. \& Sripa, B. (2017). Role of socio-cultural and economic factors in cyprinid fish distribution networks and consumption in Lawa Lake region, Northeast Thailand: Novel perspectives on Opisthorchis viverrini transmission dynamics. Acta Tropica 170: 85-94. https://doi.org/10.1016/j.actatropica. 2017. 02.010 
Khieu, V., Fürst, T., Miyamoto, K., Yong, T.S., Chai, J.Y., Huy, R., Muth, S. \& Odermatt, P. (2019). Is Opisthorchis viverrini emerging in Cambodia? Advance in Parasitology 103: 31-73. https://doi.org/10.1016/bs.apar.2019.02.002

Manpratum, Y., Kaewkes, W., Echaubard, P., Sripa, B. \& Kaewkes, S. (2017). New locality record for Haplorchoides mehrai and possible interactions with Opisthorchis viverrini metacercariae in cyprinid fished in Northeast Thailand. Parasitology Research 116: 601-608. https://doi.org/10.1007/ s00436-016-5324-7

Namsanor, J., Kiatsopit, N., Laha, T., Andrews, R.H., Petney, T.N. \& Sithithaworn, P. (2020). Infection dynamic of Opisthorchis viverrini metacercariae in cyprinid fishes from two endemic areas in Thailand and Lao PDR. The American Journal of Tropical Medicine and Hygiene 102: 110-116. https://doi.org/10.4269/ajtmh.19-0432

Namsanor, J., Sithithaworn, P., Kopolrat, K., Kiatsopit, N., Pitaksakulrat, O., Tesana, S., Andrews, R.H. \& Petney, T.N. (2015). Seasonal transmission of Opisthorchis viverrini sensu lato and a lecithodendriid trematode species in Bithynia siamensis goniomphalos snails in northeast Thailand. The American Journal of Tropical Medicine and Hygiene 93: 87-93. https://doi.org/10.4269/ajtmh.14-0639

Ngoen-klan, R., Piangjai, S., Somwang, P., Moophayak, K., Sukontason, K., Sukontason, K., Sukontasan, K.L., Sampson, M. \& Irvive, K. (2010). Emerging helminths infection in snails and cyprinoid fish in sewage treatment wetlands waters in Cambodia. Asian Journal of Water, Environment and Pollution 7: 13-21.

Pinlaor, S., Onsurathum, S., Boonmars, T., Pinlaor, P., Hongsrichan, N., Chaidee, A., Haonan, O., Limviroj, W., Tesana, S. \& Kaewkes, S. (2013). Distribution and abundance of Opisthorchis viverrini metacercariae in cyprinid fish in Northeastern Thailand. The Korean Journal of Parasitology 51: 703-710. https://doi.org/10.3347/ kjp.2013.51.6.703

Prakobwong, S., Suwannatrai, A., Sancomerang, A., Chaipibool, S. \& Siriwechtumrong, N. (2017). A large scale study of the epidemiology and risk factors for the carcinogenic liver fluke Opisthorchis viverrini in Udon Thani Province, Thailand. Asian Pacific Journal of Cancer Prevention 18: 2853-2860. https://doi.org/10.22034/APJCP. 2017.18.10.2853

Prasongwatana, J., Laummaunwai, P., Boonmars, T. \& Pinlaor, S. (2013). Viable metacercariae of Opisthorchis viverrini in northeastern Thai cyprinid fish dishes - as part of a rational program for control of $O$. viverrini-associated cholangiocarcinoma. Parasitology Research 112: 1323-1327. https://doi.org/10.1007/s00436-012-3154-9
Prasopdee, S., Kulsantiwong, J., Piratae, S., Khampoosa, P., Thammasiri, C., Suwannatrai, A., Laha, T., Grams, R., Loukas, A. \& Tesana, S. (2015). Temperature dependence of Opisthorchis viverrini infection in first intermediate host snail, Bithynia siamensis goniomphalos. Acta Tropica 141 (Part A): 112-117. https://doi.org/10.1016/j.actatropica. 2013.10.011

Praweenwongwuthi, S., Kaewmuangmoon, T., Choenkwan, S. \& Rambo, A.T. (2017). Recent changes in agricultural land use in the riverine area of Nakhon Phanom Province, Northeast Thailand. Southeast Asian Studies 6: 357-365. https://doi.org/10.20495/seas.6.2_357

Sithithaworn, P., Andrews, R.H., Van De, N., Wongsaroj, T., Sinuon, M., Odermatt, P., Nawa, Y., Liang, S., Brindley, P.J. \& Sripa, B. (2012). The current status of opisthorchiasis and clonorchiasis in the Mekong Basin. Parasitology International 61: 10-6. https://doi.org/10.1016/j.parint.2011. 08.014

Sithithaworn, P., Pipitgool, V., Srisawangwong, T., Elkins, D.B. \& Haswell-Elkins, M.R. (1997). Seasonal variation of Opisthorchis viverrini infection in cyprinoid fish in northeast Thailand: implications for parasite control and food safety. Bulletin of the World Health Organizaton 75: 125-131.

Sripa, B., Tangkawattana, S., Laha, T., Kaewkes, S., Mallory, F.F., Smith, J.F. \& Wilcox, B.A. (2015). Toward integrated opisthorchiasis control in northeast Thailand: the Lawa project. Acta Tropica 141(Part B): 361-367. https://doi.org/ 10.1016/j.actatropica.2014.07.017

Suwannatrai, A., Saichua, P. \& Haswell, M. (2018). Epidemiology of Opisthorchis viverrini infection. In: Asiatic Liver Fluke - From Basic Science to Public Health, Part A, Sripa, B. \& Brindley, P.J. (editors). Advances in Parasitology 101: 41-67. https://doi.org/10.1016/bs.apar.2018.05.002

Thaewnongiew, K., Singthong, S., Kutchamart, S., Tangsawad, S., Promthet, S., Sailugkum, S. \& Wongba, N. (2014). Prevalence and risk factors for Opisthorchis viverrini infections in upper Northeast Thailand. Asian Pacific Journal of Cancer Prevention 15: 6609-6612. https://doi.org/ 10.7314/apjcp.2014.15.16.6609

Touch, S., Yoonuan, T., Nuamtanong, S., Homsuwan, N., Phuphisut, O., Thaenkham, U. \& Waikagul, J. (2013). Seasonal variation of Opisthorchis viverrini metacercarial infection in cyprinid fish from Southern Cambodia. The Journal of Tropical Medicine and Parasitology 36: 1-7. 